\title{
Ana Maria Matute e Carmen Laforet: Romance da Geração de 50 - A Família no Pós-guerra espanhol em Primera Memoria e Nada
}

\author{
Ana Maria Matute and Carmen Laforet: Novel of the Generation of 50 - The Family \\ in the Spanish Post-W ar in Primera Memoria and Nada
}

Cristina Bezerra Rodrigues ${ }^{1}$

\begin{abstract}
RESUMO: Neste artigo, analisamos as estruturas familiares no contexto da Guerra Civil Espanhola, nas obras das escritoras espanholas Ana María Matute (Primera Memoria), e Carmen Laforet $(\mathrm{Nada})$. Através das adolescentes protagonistas, podemos reconhecer não somente as ansiedades, inquietudes e frustrações dessas jovens meninas, mas também as esperanças das autoras que viveram sob um regime autoritário limitante e opressor. Com seus discursos, romperam regras, desfizeram estereótipos, e apontaram para construções completas e singulares que representam a luta pela autoria feminina no campo literário. Através de suas obras, adotam uma postura crítica e denunciam, em uma narração realista, episódios cotidianos de um confinamento instituído às mulheres naqueles anos. Observar a estrutura familiar neste contexto bélico é identificar as transgressões exercidas pelas autoras contra os modelos estabelecidos desde o franquismo, através de personagens femininas que questionam os paradigmas impostos pela sociedade do pós-guerra espanhol.
\end{abstract}

PALAVRAS-CHAVES: Ana María Matute; Carmen Laforet; família; feminino; ditadura.

ABSTRACT: ABSTRACT: In this article, we analyze family structures in the context of the Spanish Civil War, in the works of Spanish writers Ana María Matute (First Memory), and Carmen Laforet (Nada). Through the teenage protagonists, we can recognize not only the anxieties, concerns and frustrations of these young girls, but also the hopes of the authors who lived under a limiting and oppressive authoritarian regime. With their speeches, they broke rules, broke stereotypes, and pointed to complete and unique constructions that represent the struggle for female authorship in the literary field. Through their works, they adopt a critical stance and denounce, in a realistic narration, daily episodes of a confinement instituted to women in those years. To observe the family structure in this warlike context is to identify the transgressions exercised by the authors against the models established since the Franco regime, through female characters who question the paradigms imposed by the Spanish postwar society.

KEY-WORDS: Ana María Matute; Carmen Laforet; family; female; dictatorship.

As narrativas femininas do meio século espanhol funcionavam como testemunho dos momentos empedernidos que viveram escritoras como Ana Maria Matute e Carmen Laforet, cercadas pelo cenário social do pós-guerra espanhol na adolescência. As escritoras supracitadas usaram a literatura para expressar suas vivências cotidianas, silenciadas pela

\footnotetext{
${ }^{1}$ Professora de Língua Portuguesa do Grupo SIE em Vizcaya, Espanha. Tradutora Especialista em Tradução de Português/Espanhol. E-mail: cris.bezerra.rodrigues@gmail.com.
} 
imposição de uma conduta moral hipócrita vigente naquele período ditador. Enfrentando todo o rigor e repressão, o olhar feminino avançou com uma postura crítica sobre a política social dominante.

Matute e Laforet pertencem à geração de escritores conhecido como Geração do $50^{2}$. Nessa geração os escritores não falam da guerra, já que não participaram ativamente nela, e não podem dar seu testemunho direto. São escritores que utilizaram protagonistas infantis em suas obras «que sob um olhar inocente se filtra o mundo fratricida dos mais velhos, cujos comportamentos remedam com um mimetismo de dramáticas consequências» ${ }^{3}$.

$\mathrm{Na}$ Espanha, segundo Gurruchaga ${ }^{4}$, o gênero narrativo escrito por mulheres começa a destacar-se entre os anos quarenta e cinquenta. Embora comecem a escrever e publicar nessa época, salvo raras exceções, as referidas escritoras foram ignoradas. Somente se destacam algumas galardoadas com algum prêmio literário importante, e somente a partir dos anos oitenta, publicam ensaios considerados relevantes, com posterioridade e reconhecimento tardio.

O desafio dessas escritoras era inserir a literatura de mulher em um cânon literário monopolizado pelo varão, e após a atonia surge finalmente uma lista considerável de escritoras que criaram sua própria escrita e se afastaram das escolas e tendências estabelecidas pela crítica, embora estivessem incluídas em algumas correntes literárias.

Antes de nos adentrar nas obras das autoras em questão, mister se faz a compreensão do processo histórico da Guerra Civil Espanhola (1936-1939). Até então, a Espanha tinha avançado em mudanças políticas e aspectos sociais realizados com os governos da República, como o direito ao voto, a separação entre os poderes da igreja e do estado, e a igualdade entre os homens e as mulheres, entre outros avanços. Embora a sociedade tenha se radicalizado em suas posições políticas, a instabilidade e graves conflitos gerados pelo caráter transformador e reformista do republicanismo, sofreram influencias do comunismo soviético revolucionário. Os espanhóis enfrentaram um violento embate cujas consequências fizeram com que o país retrocedesse no processo de avanço histórico que caminhava na direção do progresso no âmbito do social, cultural e literário.

A Guerra Civil se iniciou em julho de 1936, quando uma parte do exército espanhol se sublevou contra o governo vigente dentro desse contexto de polarização e radicalização

\footnotetext{
2 A Geração de 1950 também foi denominada como: realismo histórico, sessentista, realismo social, e também bastante conhecida como los niños de la guerra.

${ }^{3}$ Véase S. Sanz Villanueva, Historia de la literatura española 6/2, 1984, p.37-38 [Tradução nossa].

${ }^{4}$ Véase L. M. Gurruchaga, Discurso de autora: género y censura en la narrativa española de posguerra, 2010, p. 49. Algumas escritoras embora respaldadas por prêmios importantes foram relegadas ao esquecimento. Vale destacar Concha Alós, Mercedes Ballesteros, Teresa Barbero, Rosa María Cajal, Concha Castroviejo, Paulina Crusat, Mercedes Formica, entre outras.
} 
política da sociedade espanhola. O extremismo ideológico conduziu a situação política pela via da violência, em um processo crescente até que estalou a conflagração civil de uma maneira tão cruel que levou o país a uma guerra devastadora que o destruiu não somente economicamente, mas também socialmente. Como resultado da contenda, foi instaurado um regime ditatorial de ideologia fascista: o Franquismo.

O General Francisco Franco, em seu governo, executou férreas políticas de extrema direita e uma brutal repressão contra os derrotados pela guerra; impôs sua ideologia e perseguiu ferozmente a oposição; por fim, vituperou por completo as democracias europeias vizinhas. A guerra que irrompeu na Europa, imediatamente depois à guerra espanhola, se alinhou em princípio com o eixo de Hitler e Mussolini, embora sem chegar a participar diretamente na contenda, e quando mudou o foco da guerra, foi-se acercando cada vez mais aos EUA, até converter-se em um fiel aliado anticomunista.

As diversas categorias da sociedade sofreram de maneira geral, embora em diferentes medidas, com o regime de Franco e seu poder autoritário. A Espanha passou a ser uma espécie de monarquia absoluta regressiva, mas governada por um líder erguido ao poder por meio da violência, ao invés de seguir uma dinastia com um rei legitimado por uma tradição. Os espanhóis viviam de acordo com as tradições da burguesia católica, que impunha uma reconstrução baseada na ideologia mais conservadora, o que constituiu um retrocesso histórico-social.

Depois da guerra civil, as cidades se transformaram em ruínas, as indústrias estavam em lamentáveis condições, os campos improdutivos, os meios de comunicação silenciados, os transportes quebrados, e como consequência, um desemprego extenso minava as estruturas familiares que sobreviveram ao caos da guerra. Devido à migração de uma grande massa de pessoas do campo para a cidade, cresceu a prostituição feminina e as relações familiares se espedaçavam cada vez mais. Em um contexto de casamentos desgastados e lares desfeitos, a miséria ameaçava em arruinar a todos. Devido a uma herança machista enraizada na sociedade, a busca pela autoafirmação fazia crescer a exploração feminina e o sofrimento pessoal e social das mulheres.

Franco incentivou a manutenção da família no modelo patriarcal e religioso, já que a população masculina foi afetada com a morte dos jovens milicianos durante a guerra. $\mathrm{O}$ objetivo era que aumentasse aceleradamente a população masculina no país para fazer da Espanha uma potência europeia. A família passou a ser influenciada não somente pelas coordenadas políticas e econômicas de Franco, mas também pelos hábitos e 
comportamentos determinados pelo regime e pela doutrina religiosa extrema que absolutizava.

O caminho da mulher na Espanha do pós-guerra foi árduo, o papel da mulher se restringia à recomposição dos lares destruídos e dizimados pela guerra, e para isso o governo facilitava empréstimos, ajudas sociais e leis para realizar casamentos e proteger as famílias. A Seção Feminina de Pilar Primo de Rivera foi criada como um aparelho de propaganda franquista, e contribuiu para materializar os postulados franquistas e religiosos: as mulheres do pós-guerra tinha o dever de formar famílias sólidas e alegres em um contexto social desestruturado e sombrio, como ángeles del hogar [anjos do lar]. A investigadora Núñez Puente resume esse período quando diz que:

A ditadura franquista trata de reconstruir, ou melhor, de construir, um novo modelo de mulher espanhola e católica. Uma mulher que deveria fazer da religião e da família o centro de sua existência ... Quanto menos soubesse e quanto menos notícias tivesse do que acontecia no resto do mundo, mais fácil seria mantê-la nos limites do que se considerava um comportamento adequado para uma mulher (PUENTE, 2014, pp. 96-7).

Não obstante, houve um avanço com a presença feminina no mercado de trabalho e as mulheres se tornaram cada vez mais ativas na vida pública. Lutando diante do desespero extremo por alimentar seus filhos, muitas foram conquistando algo que Franco temia muito: a consciência, o desejo de libertar-se da repressão imposta pelo ditador e pela igreja.

Assim, apesar da intolerância política e da proibição, algumas mulheres se atreveram a escrever para expressar suas dores e angústias naquele ambiente hostil, e algumas se dedicaram a lutar contra a ideologia imposta. Outras, como Ana Maria Matute e Carmen Laforet, escreveram como uma maneira de viver nessa realidade e contestá-la, se posicionavam contra a domesticação, a censura e a igreja, e respaldavam a intelectualidade da mulher com uma escrita intimista.

Com a palavra narrativa de Matute, Laforet e de muitas outras ${ }^{5}$, a Espanha recebe um sopro de ânimo no pós-guerra, começa a surgir uma literatura que busca criar sua própria identidade construindo uma consciência de mulher em sua dimensão de indivíduo social e utilizando personagens femininos que recriaram o doloroso despertar da vida adulta. Embora muitas vezes fossem tachadas de insignificantes pela crítica masculina, receberam também críticas positivas. Elas plasmaram, em suas obras, a fome, a morte, a

\footnotetext{
${ }^{5}$ Rosa Chacel (Memorias de Leticia Valle); Eulalia Galvarriato (Cinco Sombras); Susana March (Nina); Dolores Medio (Nosotros los Ribero).
} 
solidão que sentiram, denunciando as mazelas vividas naquele período fatídico de horror e desesperança.

Primera Memoria, de Ana Maria Matute, é o despertar da adolescência em que vão desaparecendo os últimos sonhos de infância. Nesse trânsito entre a infância e a idade adulta está Matia, a protagonista adolescente de doze anos que vive sob os cuidados de uma avó déspota em uma ilha do Mediterrâneo. Ali, ela compartilha com seu primo Borja não somente a singeleza da juventude, mas também convive com as fraquezas, debilidades e mentiras de um primo mau caráter, mentiroso e ladrão. O melhor e único amigo de Matia é Manuel, filho de Los Taronjí, uma família discriminada na ilha por acreditar na vitória dos republicanos. Manuel representa a bondade e integridade em um mundo vil e falso. A mãe do Borja, a tia Emília, é uma autêntica espanhola submissa, obediente, resignada e oprimida aos mandos da mãe Práxedes. Vive fechada no lar à espera de seu marido general.

Em Primera Memoria, a autora trata dos problemas de sua época como consequência da guerra civil espanhola. A guerra estalou em 1936, quando Matute tinha somente dez anos, e quando acabou a ditadura de Franco, ela tinha 49 anos de idade. A obra pertence à trilogia Los Mercaderes ${ }^{6}$, e constitui não somente a representação do mundo vivido pela autora, mas também uma forte crítica daquele sistema social que, em decorrência da guerra, tornou-se desumanizador. A obra ganhadora do Prêmio Nadal, nos dá o ponto de vista dos vencidos: o mundo infantil diante do mundo adulto que sempre sai vencedor, e a solidão devastadora dos personagens infantis que estão condenados a um olhar eternamente nostálgico.

Nada de Carmen Laforet, obra ganhadora do Prêmio Nadal, narra a história da adolescente órfã Andrea que decide mudar-se para Barcelona a fim de estudar Filosofia e Letras. Abandona sua cidade aos dezoito anos e vai viver com uns parentes. Laforet descreve o ambiente tenso do pós-guerra marcado pelo trauma coletivo que sofreu o país, e embora terminada a guerra, persistia o sofrimento sob a pressão de Franco. Os habitantes da rua Aribau apresentam comportamentos desequilibrados, evidenciando a instabilidade de seus estados mentais. Román, um dos tios de Andrea, é um homem talentoso, mas indolente, possuidor de uma arrogância repulsiva; Juan, o outro tio, é trabalhador, mas sem talento, e muito violento; Gloria, esposa de Juán, aparenta rebeldia, mas o que predomina é uma ignorância pretensiosa; Angustias, a tia representante da religiosidade fanática, tenta

\footnotetext{
${ }^{6}$ É uma trilogía que começa com a publicação de Primera Memoria (1960), que ganha o prêmio Nadal, em seguida publica-se Los Soldados Lloran de Noche (1964), que recebe o Prêmio Fastenrath em 1969, e por último La trampa (1969).
} 
domesticar Andrea; a avó que vive atormentada e enclausurada em sua tradição, alude à guerra todos os atos violentos da família; e Antonia, uma criada rude e ignorante, portadora do poder político do lar.

Laforet compôs um retrato daquele período bélico, e expôs com clareza que as vítimas da guerra não são somente os que jazem nos cemitérios, ou os que levam pro resto da vida algum tipo de mutilação física, mas também os seres como os da rua Aribau de Barcelona, aparentemente imaculados, porém trazendo na alma as marcas daquele tempo: crueldade, ignorância, falsa religiosidade, egoísmo, intransigência, sede de poder e uma profunda solidão. Andrea se defronta assim em uma tragédia ao se chocar com uma dura realidade, a de conviver com a mesquinhez daquelas pessoas transformando suas ilusões em nada.

Em Primera Memoria e Nada, há uns temas coincidentes, como por exemplo, a ausência materna das protagonistas femininas. Matia, de Primera Memoria, é órfã de mãe, e seu pai está na guerra lutando a favor dos republicanos. Foi educada por sua aia, passando depois aos cuidados de sua avó Práxedes. Já Andrea de Nada, é também órfã, vivia com uma prima até os dezoito anos, logo toma a valente decisão de mudar-se para Barcelona para estudar na Faculdade de Filosofia e Letras, passando a viver com sua avó e tios. As protagonistas femininas se caracterizam pela ausência materna, e se observa o vazio de um modelo ideal a seguir.

Uma das grandes marcas das narrativas de Matute e Laforet é a desestruturação familiar patriarcal, ou crise do patriarcado. Nos "corpus literários" analisados há um debilitamento de um modelo de família baseado na autoridade e dominação sobre as mulheres. Podemos observar uma transição a outro modelo de estrutura familiar através da deslegitimação de valores conservadores.

A teórica do feminismo Celia Amorós assume a definição da feminista Heidi Hartmann, e define o patriarcado «como um conjunto de relações sociais entre os homens que têm uma base material e que, se são hierárquicas, estabelecem ou criam uma interdependência e solidariedade entre os homens que lhes permite dominar as mulheres» ${ }^{7}$. Não é nossa intenção adentrar-nos no que originou o patriarcalismo, mas sabemos que esse sistema foi construído tendo como pilares as apropriações, hierarquias, inimizades, guerras, lutas, obediências, dominação e controle.

Segundo Isolina Ballesteros, graças ao pós-modernismo o indivíduo foi conduzido para novas formas de experiência, subjetividade e cultura:

\footnotetext{
${ }^{7}$ Hartmann apud Amorós, 2005, p. 113-114. Tradução nossa.
} 
O pós-modernismo afronta os discursos dominantes do mundo ocidental a uma crise de legitimação, que vem dada através do questionamento de seus pressupostos principais: o Homem, o Sujeito, a Verdade, a História ... Neste sistema de representação ocidental, a mulher é excluída da cena e se converte em figura ou "representação" do irrepresentável (a natureza, a verdade, o sublime, etc.). O pósmodernismo se instala nos limites entre o representável e o irrepresentável, para assim criticar um sistema de poder que autoriza certas representações a custo de invalidar e impossibilitar outras. Se apresenta como uma época de crise de autoridade cultural, interessada em múltiplas narrativas menores às que se lhes negaram a legitimidade (BALLESTEROS, 1994, pp. 12-3).

A escrita feminina existe, portanto, para evitar a morte do outro, é uma subversão à hierarquia dominante para se afastar do discurso masculino. A crise patriarcal é simplesmente a andadura da mulher na construção de seu próprio espaço, e seus personagens femininos se erguem «no sujeito que representa a negação essencial da ordem falogocêntrica ${ }^{8}$.

Nas obras analisadas, ao se ausentarem as figuras paternas das personagens de Matia e de Andrea, que tradicionalmente representa a figura de autoridade, esse papel passa a ser transferido a outro membro familiar. A ausência materna, testemunhada com o desaparecimento desses dois membros familiares, induz o poder da estrutura familiar à avó, no caso de Matia, de Primera Memoria, já que Dona Práxedes assume o rol de autoridade, e se converte em substituta do pai e da mãe ao mesmo tempo. Práxedes passa a ser a orientadora e transmissora dos valores de seus progenitores e tem como objetivo transformar Matia em uma senhorita representante do ideal falangista, a adolescente resiste, mas a matriarca tenta moldá-la segundo a tradição conservadora nacionalista espanhola:

\footnotetext{
A avó se preocupava muito com meus dentes — demasiado separados e grandese com meus olhos («Não olhe assim, de viés.» «Não feche as pálpebras.» « Meu Deus, essa criatura tem o olho direito torto!»). Preocupava-se com meu cabelo, liso até o desespero, e se preocupava também com minhas pernas: — Estão tão finas... Deve ser coisa da idade. [...] Sentada em sua cadeira de balanço, me examinava com seus olhos redondos de coruja, me obrigava a andar e a sentar-me, olhava minhas mãos e olhos [...] Criticava a cor tostada de minha pele e as sardas que nasciam, por causa do sol, ao redor do nariz. - Sempre ao sol, como uma pivete! Meu Deus, que desastre: boca grande, olhos separados... Não feche os olhos assim! Vai ficar com rugas. Levanta os ombros, a cabeça... Morda e molhe os lábios (MATUTE, 2014, p. 114).
}

O poder de Dona Práxedes funciona como marca do masculino ausente, o pai ausente, um ente controlador. Embora Matia esteja rodeada por mulheres, os homens de seu entorno são adolescentes. Entretanto essa unidade familiar não gera uma verdadeira união entre as mulheres, já que a ideologia sexista que projeta Dona Práxedes, provoca que cada indivíduo se feche em seu próprio mundo.

\footnotetext{
${ }^{8}$ Ibíd., p. 21.
} 
Matia não aceita que a domestiquem, enfrenta assim uma realidade dura e cruel e começa a aflorar a conscientização de se encontrar em um mundo incompreensível que a estimula a obedecer às normas que ela recusa: "De repente se rasgou a sutil neblina, o véu, que ainda me mantinha afastada do mundo. De uma forma brutal apareceu tudo aquilo que eu resistia em conhecer"”. Lutar contra a obediência inquestionável de Dona Práxedes, ou sobre o estabelecido pela sociedade da época, é a maneira de Matia de se conscientizar, e superar a obediência muda.

Em relação à Andrea, órfã aos dezoito anos, ao mudar-se pra Barcelona depara-se com um ambiente familiar em ruína, teias de aranha por toda parte, uma casa com abundantes e inúteis objetos, em um estado de terrível sujeira. O romance alude à ruína financeira da família e apresenta personagens cujos comportamentos violentos e incontroláveis, representam a instabilidade de seus estados mentais.

A tia Angustias representa um papel importante na primeira fase de amadurecimento de Andrea. É uma mulher solteirona, frustrada por um amor nunca realizado, impõe severas restrições a Andrea, e tenta controlar tudo o que ocorre na casa e dominar a toda a família. A chegada de Andrea é para Angustias uma nova oportunidade de manifestar seu caráter autoritário, portanto, assume ante ela um papel maternal que se revela em contínuas tentativas de controle com o propósito de moldar a conduta da jovem à sua maneira: "Te direi de outra forma: você é minha sobrinha; portanto, uma menina de boa família, comportada, cristã e inocente. Se eu não me ocupasse com tudo, você em Barcelona encontraria uma multidão de perigos. Portanto, quero te dizer que não te deixarei dar um passo seque sem minha permissão"10.

Angustias leva uma rotina entediante marcada por um grande vazio emocional. Uma mulher que foi submetida às convenções da sociedade patriarcal, renuindo qualquer possibilidade de mudança. Escandaliza-se diante das ideias de Andrea porque lhe parece uma ameaça ao ambiente familiar tradicional. As relações entre ambas refletem o clássico conflito de gerações em todo processo de amadurecimento. É a típica representante do mundo convencional que se embate com o entusiasmo dos sonhos de uma adolescente.

A única possibilidade para a jovem escapar da subjugação de uma tia déspota é a rebeldia, que não chega a concretizar-se porque Angustias decide viver em um convento, assim, a adolescente ganha liberdade e novas oportunidades de crescimento em sua nova etapa de amadurecimento. Andrea busca refúgio na cordialidade de suas relações

\footnotetext{
${ }^{9}$ Ibíd., p. 223.

${ }^{10}$ Laforet, Carmen, Nada, 1990, p. 26 [Tradução nossa].
} 
universitárias, embora pertencentes à outra classe social, seus amigos, em especial Ena, lhe confere momentos belos e aliviam um pouco a sensação angustiosa da fome.

Segundo Pérez, a vasta presença de adolescentes nas narrativas de pós-guerra, personifica a rebeldia ante às normas, ao mesmo tempo que justifica melhor um comportamento desviado, « ao produzir-se em uma idade emocionalmente instável como é o trânsito à vida adulta» ${ }^{11}$. A adolescência em si é uma etapa de transição em que o adolescente, antes situado no entorno familiar, passa a construir relações de amizade compartilhando afeições, hábitos, inquietudes, ilusões, mas que ainda não estão identificados com o amadurecimento. O que fizeram Matute e Laforet em suas obras, através de suas adolescentes, foi romper com os moldes opressores e lutar contra a dura realidade: "A adolescente desviada não quer seguir aceitando uma imposição histórica que a discrimina injustamente e cujas causas não compreende. Somente está segura de que não tem intenção de repetir a existência de resignação desolada que lhe legaram" (PERÉZ, 2001, p. 196).

Seguindo com Pérez, essas protagonistas não acreditam no mito da mulher ideal e da mãe abnegada, estão cansadas de reproduzir modelos que as subjugam, e surgiu assim, um conflito de identidade que afetou a muitas mulheres daquela época na Espanha. Jovens como Matia e Andrea começam a dizer não às normas, começam a romper com o estabelecido "porque foi o começo de um final pressentido para a escravidão moral da mulher promovida pela ditadura ${ }^{12}$. Era muito frequente naqueles tempos de ditadura, utilizar o recurso de isolamento das protagonistas, para separá-las da mediocridade reinante e para isolá-las da intolerância coletiva. A luta da adolescente contra a realidade adversa que a circunda, a leva ao isolamento e à busca da paz interior, ao refúgio, à solidão como fizeram nossas protagonistas:

Matia: "Alicia no mundo do espelho», pensei, mais de uma vez, contemplando-me nele, desnuda e desolada, com um grande desejo de atravessar sua superfície, que parecia gelatinosa. Tristíssima imagem aquela-a minha-, de olhos assustados, que era, talvez, a imagem mesma da solidão" (MATUTE, op. cit), enquanto Andrea: "Se aquela noite-pensava eu-, se tivesse acabado o mundo ou se tivesse morrido um deles, sua história haveria ficado completamente fechada e bela como um círculo. Assim acontecia nos romances, nos filmes, mas não na vida... Estava me conscientizando, pela primeira vez, de que tudo segue, fica cinza, se arruína vivendo. De que nossa história não tem final até que chega a morte e o corpo se desfaz" (MATUTE, op. cit.).

A desestruturação familiar causada pela orfandade e por não encontrar em seus familiares um modelo a seguir, faz com que essas protagonistas se sintam sozinhas e

\footnotetext{
${ }^{11}$ Véase Galdona Pérez, Discurso femenino en la novela española de posguerra: Carmen Laforet, Ana María Matute, Elena Quiroga, 2001, p. 196. Tradução nossa.

12 Ibíd., p. 202.
} 
isoladas do resto da família, e também da sociedade em que estavam inseridas. É uma solidão emocional "porque não sabem ou não podem lutar contra a marginalização e a desigualdade em que vivem em relação ao homem"13. Ser mulher para essas meninas é como algo misterioso e asfixiante que lhes tira a liberdade. O que une o destino dessas adolescentes analisadas é a solidão de uma liberdade truncada que compartem em um destino soçobrado.

A estrutura familiar daquelas épocas de ditadura é fruto das construções ideológicas da casa familiar representativa da Espanha de Franco. Matute e Laforet utilizaram um dos mecanismos subversivos mais frequentes nas narrativas do pós-guerra, que é a ausência de um modelo familiar tradicional de pai, mãe e filhos. As meninas protagonistas movem-se dentro de um ambiente familiar despedaçado, seja pela ausência paterna, materna, ou por qualquer outro desajuste nessa estrutura conservadora. Essa desconstrução familiar acarreta às protagonistas a perda da inocência junto à tomada de consciência de seu lugar na sociedade.

Segundo Colmeiro, em Primera Memoria, e aqui incluímos Nada pelas mesmas características: "A casa e a família funcionam... como microcosmos da nação. A tensão do drama familiar interior atua simbolicamente como reflexo do conflito social exterior, da guerra fratricida e da repressão na retaguarda nacional. Se observa um patente cainismo simbólico que penetra todos os cantos da casa e do romance” (COLMEIRO, 2005, p. 62).

Paul Ilie, em sua obra Literatura y exilio interior, embora não mencione as obras analisadas, afirma que "hierarquia familiar serve como modelo de estruturas autoritárias que se parecem, em outro lugar do paradigma, ao governo político" ${ }^{\text {"14 }}$. Assim, Matute e Laforet ao desconstruírem o adestramento da ordem franquista, valendo-se da ausência de uma estrutura familiar tradicionalista, contribuem através de Matia e Andrea, em romper o cerco imposto à mulher daquele contexto, destacando o brilho dos personagens transgressores.

Assim, deslindamos que toda discussão sobre a importância da estrutura familiar, é fruto de construções ideológicas. Essas relações familiares que analisamos nos romances funcionam como respostas ao discurso hegemônico. As novelas de Matute, Laforet e de muitas outras, como contraponto ao discurso dominador que apela à família como uma maneira de controlar os membros de suas sociedades, e que se ergue como modelo homogêneo nacional para moldar e controlar a coletividade, utilizam o mecanismo da

\footnotetext{
${ }^{13}$ Véase M.G.Cabedo, La madre ausente en la novela femenina de la posguerra española: pérdida y liberación, 2013. O livro que disponho está na versão eletrônica, e não apresenta numeração em suas páginas, o texto pode-se encontrar na introdução.

${ }^{14}$ Véase Paul Ilie, Literatuta y exilio interior, 1981, p. 257. Tradução nossa.
} 
desestrutura familiar como um despertador para um panorama cultural tão devastado e sem esperanças como o da Espanha nos tempos de ditadura.

Matute e Laforet repeliram uma hipocrisia que foi coletivamente admitida, a de uma sociedade cristã irrepreensível onde se exigia da mulher, o papel de excelente esposa e mãe abnegada. Essas mulheres escritoras criaram uma (des) ordem social tomando a palavra sem permissão, questionando e deslocando os róis estabelecidos pela sociedade. Através de suas narrativas, as escritoras analisadas nos oferecem uma clara visão da ideologia dominante que fomentou essa situação de opressão. Escrever para elas era uma maneira de tomar consciência do mundo parra assim subvertê-lo.

Posicionaram as protagonistas em um choque direto com um sistema que além de oprimi-las, tenta defini-las. As autoras dessacralizam a maternidade desafiando o discurso oficial do governo ditatorial da Espanha. A literatura se ergue então, como arma de resistência. Embora não consigam romper totalmente com o discurso hegemônico, elas se erguem como protagonistas da história de um país, e nos faz reinstaurar um diálogo com o passado, para assim refletirmos sobre o presente, e incidir no futuro.

\section{REFERÊNCIAS}

ALBORG, Concha. "Madres e hijas en la narrativa española contemporánea escrita por mujeres: ¿mártires, monstruos o musas?" in: Mujeres novelistas en el panorama literario del siglo XX. Cuenca: Álvarez Marina Villalba, Universidad de Castilla-La Mancha, 2000.

AMORÓS, Celia. Feminismo y filosofía. Madrid: Editorial Síntesis, 2000. La gran diferencia y sus pequeñas consecuencias...Para las luchas de las mujeres. Madrid: Cátedra, 2005.

BALLESTEROS, Isolina. Escritura femenina y discurso autobiográfico en la nueva novela española. Nova York: Peter Lang, 1994.

CLEARY NICHOLS, Geraldine. Escribir espacio propio: Laforet, Matute, Moix, Tusquets, Rieray Roig por si mismas. Minneapolis: The Institute for the Study of Ideologies and Literature, 1989.

COLMERIO, José F. Memoria histórica e identidade cultural: de la postguerra a la postmodernidad. Barcelona: Anthropos Editorial, 2005.

DE CASTRO GARCÍA, María Isabel, "Novela española contemporánea. El Nuevo Realismo y la sociedad representada. Una perspectiva desde la novela de mujer. In: Actas XXI Simposio Internacional de Literatura. Literatura y Sociedad. Madrid: UNED Ediciones, 2003.

DOMINGUEZ, Nora. De donde vienen los niños. Maternidad y escritura en la cultura argentina. Rosario: Beatriz Viterbo, 2007. 
GALDONA PÉREZ, Rosa Isabel. Discurso femenino en la novela española de posguerra: Carmen Laforet, Ana Maria Matute y Elena Quiroga. Santa Cruz de Tenerife: Universidad de La Laguna, 2001.

GALLEGO MÉNDEZ, María Teresa. Mujer, falange y franquismo. Madrid: Taurus,1983.

GAZARIAN-GAUTIER, Marie-Lise. Ana María Matute. La voz del silencio. Madrid: EspasaCalpe, 1997.

ILIE, Paul. Literatura y exilio interior. Madrid: Editorial Fundamentos, 1981.

LAFORET, Carmen. Nada. Barcelona: Planeta, 1990.

MARTIN GAITE, Carmen. Usos amorosos de la postguerra española. Barcelona: Anagrama, 2001.

MATUTE, Ana María. Primera Memoria. Barcelona: Planeta, 2014.

MONTEJO GURRUCHAGA, Lucía, "Las mujeres escritoras de los años cincuenta: al margen de las tendencias dominantes", en Las mujeres escritoras en la historia de la Literatura Española. Madrid: UNED Ediciones, 2002. . Literatura Española. Madrid: UNED Ediciones, 2003.

Discurso de autora: género y censura en la narrativa española de posguerra. Madrid: UNED

Ediciones, 2010.

NAVAS OCAÑA, María Isabel. La literatura española y la crítica feminista. Madrid:

Fundamentos, 2009.

NÚNEZ PUENTE, Sonia. Una historia propia: historia de las mujeres en la España del siglo XX. Madrid: Pliegos, 2004.

REDONDO GOICOECHEA, Alicia. La narrativa de Ana María Matute In: Mujeres novelistas en el panorama literario del siglo XX: I congreso de narrativa española. Toledo: Estudios, 2000.

RICH, Adrienne. Nacemos de mujer: la maternidad como experiencia e institución. Madrid: Cátedra, 1996.

RIDDEL, María del Carmen. La escritura femenina en la postguerra española. New York: Peter Lang, 1995.

SANZ VILLANUEVA, Santos. Historia de la literatura española. Barcelona: Ariel, Gredos, 1984.

2010.

La novela española durante el franquismo: itinerarios de la anormalidad. Madrid: Gredos,

VEGETTI FINZI, Silvia. El niño de la noche: hacerse mujer, hacerse madre. Madrid: Cátedra, 1992.

VILANOVA, Antonio. Novela y Sociedad en la España de la Posguerra. Barcelona: Lumen, 1995. 